\title{
Síntese de trans-resveratrol e controle de podridão em maçãs com uso de elicitores em pós-colheita
}

\author{
Cláudia Kaehler Sautter ${ }^{(1)}$, Lindolfo Storck(1), Mara Regina Rizzatti(2), \\ Carlos Augusto Mallmann(1) e Auri Brackmann(1)
}

\begin{abstract}
(1)Universidade Federal de Santa Maria, Centro de Ciências Rurais, Avenida Roraima, no 1.000, Cidade Universitária, Bairro Camobi, CEP 97105-900 Santa Maria, RS. E-mail: kaehler@terra.com.br, lindolfo@smail.ufsm.br, mallmann@smail.ufsm.br, auribrackmann@gmail.com (2)Pontifícia Universidade Católica do Rio Grande do Sul, Centro de P\&D/GFR, Avenida Ipiranga, no 6681, Prédio 96A-104, CEP 90619-900 Porto Alegre, RS. E-mail: marar@pucrs.br
\end{abstract}

Resumo - O objetivo deste trabalho foi avaliar o efeito da aplicação de elicitores abióticos na biossíntese de resveratrol e na indução de resistência à podridão pós-colheita de maçãs 'Gala' e 'Fuji'. Foram realizados os tratamentos: radiação ultravioleta, fosfito e acibenzolar-S-metil - aplicados antes do armazenamento - e ozônio - aplicado intermitente durante o armazenamento. As condições de armazenamento foram: 'Gala', 1,5 kPa de $\mathrm{O}_{2}$ e $2,5 \mathrm{kPa}$ de $\mathrm{CO}_{2}$, a $0,5 \pm 0,1^{\circ} \mathrm{C}$, por oito meses, e 'Fuji', $1,0 \mathrm{kPa}$ de $\mathrm{O}_{2}$ e $<0,5 \mathrm{kPa}$ de $\mathrm{CO}_{2}, \mathrm{a}-0,5 \pm 0,1^{\circ} \mathrm{C}$, por sete meses. $\mathrm{O}$ delineamento experimental foi inteiramente ao acaso, com oito repetições de 25 frutos. Na casca dos frutos, determinou-se: trans-resveratrol, polifenóis totais, antocianinas totais e diâmetro de lesão, após inoculação de Penicillium sp. no ferimento. Analisou-se na polpa: firmeza de polpa, acidez titulável, sólidos solúveis totais, açúcares redutores e não-redutores. Os elicitores não alteram a concentração de polifenóis totais e antocianinas, com exceção do acibenzolar-S-metil que reduz o conteúdo de antocianinas na maçã 'Gala'. Os elicitores induzem, na 'Fuji', mas não na maçã 'Gala', a síntese de trans-resveratrol na seqüência: acibenzolar-S-metil $>$ fosfito $\geq$ irradiação UV-C $\geq$ ozônio. Na maçã 'Gala', o fosfito reduz a ocorrência de podridão, porém, em ambas as cultivares, não há correlação entre síntese de trans-resveratrol e controle de podridão.

Termos para indexação: Malus domestica, Penicillium, acibenzolar-S-metil, fosfito, ozônio, UV-C.

\section{Synthesis of trans-resveratrol and rotting control in apples with use of elicitors in post-harvest}

\begin{abstract}
The objective of this study was evaluate the effect of the application of abiotic elicitors of resveratrol in 'Gala' and 'Fuji' apples, and rotting control. The treatment was with ultraviolet irradiation, phosphite and acibenzolar-S-methyl, applied before controlled atmosphere storage and ozone, applied so intermittently during storage. The storage conditions were: 'Gala' $\left(1.5 \mathrm{kPa} \mathrm{O}_{2}\right.$ and $2.5 \mathrm{kPa} \mathrm{CO}_{2}$, at $0.5 \pm 0.1^{\circ} \mathrm{C}$ by eight months) and 'Fuji' ( $1.0 \mathrm{kPa} \mathrm{O}$ and $<0.5 \mathrm{kPa} \mathrm{CO}$, at $-0.5 \pm 0.1^{\circ} \mathrm{C}$ for seven months). The experimental design was a completely randomized with eight repetitions of 25 fruits. In the skin of fruit trans-resveratrol were analyzed by high performance liquid chromatography; total polyphenols and anthocyanins by spectrophotometry and diameter of injury after inoculation by Penicillium sp. Firmness, acidity, total soluble solids, and reducing and non-reducing sugars were analyzed in the flesh. The elicitores do not change the concentration of phenols and anthocyanins, with the exception of the loss of total anthocyanins with acibenzolar-S-methyl in 'Gala' apple. The elicitors induce in 'Fuji' apples the synthesis of trans-resveratrol in the sequence: acibenzolarS-methyl $>$ phosphite $\geq U V-C$ irradiation $\geq$ ozone. There isn't correlation between synthesis of trans-resveratrol and rotting control, but the phosphite controlled rot in 'Gala'.
\end{abstract}

Index terms: Malus domestica, Penicillium, acibenzolar-S-methyl, phosphite, ozone, UV-C.

\section{Introdução}

O armazenamento em atmosfera controlada (AC) é mais eficaz, para manutenção da qualidade de maçãs, do que o armazenamento refrigerado, mas ainda assim ocorrem perdas significativas decorrentes principalmente de podridões. A legislação brasileira (Brasil, 2001) coloca grande restrição ao uso de fungicidas após a colheita, por causa dos resíduos neles contidos, o que pode oferecer risco de intoxicação ao

Pesq. agropec. bras., Brasília, v.43, n.9, p.1097-1103, set. 2008 
consumidor. Uma alternativa para conferir proteção ao fruto é estimular a produção de substâncias naturais, entre elas as fitoalexinas, para aumentar a resistência ou para controlar o patógeno, durante o armazenamento e a vida de prateleira. As fitoalexinas são metabólitos secundários, antimicrobianos, produzidos pela planta em resposta a estresses físicos, químicos ou biológicos. O modo de ação sobre os fungos inclui granulação citoplasmática, desorganização celular, ruptura da membrana celular e inativação de enzimas fúngicas (Schwan-Estrada et al., 2000). Os agentes ativadores dessa resistência denominam-se elicitores, que podem ser bióticos ou abióticos. Entre os abióticos destacam-se a irradiação ultravioleta do tipo C (UV-C), o ozônio e o acibenzolar-S-metil (ASM). Também há o fosfito, um fertilizante foliar, que tem apresentado efeito no controle de podridões em maçãs armazenadas (Brackmann et al., 2004), contudo não existem informações de que sua atuação seja como elicitor.

A irradiação ultravioleta, o etileno e o ozônio estimulam a produção do resveratrol em uvas na pós-colheita (Grimmig et al., 2002; Artes-Hernández et al., 2003). O resveratrol é uma fitoalexina produzida por uvas em resposta ao estresse de elicitores bióticos (Botrytis cinerea, Plasmopora viticula) e também abióticos como UV-C e ozônio (Adrian et al., 2000; Grimmig et al., 2003). Essa fitoalexina é um polifenol da classe dos estilbenos, apresentando-se sob dois isômeros (trans-3,5,4'-trihidroxiestilbeno) e cis-resveratrol (cis-3,5,4'-trihidroxiestilbeno). O isômero trans-resveratrol tem reconhecidas atividades biológicas e algumas delas são de uso terapêutico, tais como ação antiinflamatória, para redução do risco de aterosclerose, inibição da enzima lipoxigenase e ação anticarcinogênica (Pinto et al., 1999; Frémont, 2000).

O controle da podridão em plantas pode ser eficiente pela resistência sistêmica adquirida que envolve o ácido salicílico como sinalizador (Durrant \& Dong, 2004). Um ativador químico de resistência de plantas a doenças, aplicado a campo, é o acibenzolar-S-metil (ASM ou benzotiadiazol). Esse produto não tem ação direta sobre o patógeno, mas sua estrutura espacial, semelhante ao ácido salicílico, parece desenvolver papel importante na transdução de sinal (Conrath et al., 2001). O ASM é rapidamente absorvido pelos tecidos foliares e confere à planta aumento de resistência. Em pós-colheita, tem sido pesquisada a ação do ASM em maçãs 'Golden Delicious', no combate ao
Penicillium expansum e Botrytis cinerea (Spadaro et al., 2004), e em melão (Huang et al., 2000).

$\mathrm{O}$ fosfito - pentóxido de fósforo $\mathrm{P}_{2} \mathrm{O}_{5}-$ é um ânion obtido da neutralização do ácido fosfônico formalmente chamado de ácido fosforoso $\mathrm{H}_{3} \mathrm{PO}_{3}-$ com álcalis, rapidamente absorvido pela planta e translocado pelo xilema e, posteriormente, pelo floema (Guest \& Grant, 1991). A ação desse composto é controvertida, pode atuar como adubo foliar ou como fungicida tópico, dependendo da concentração e do cátion covalente, e também como indutor de resistência na planta (Guest \& Grant, 1991). Resultados satisfatórios foram obtidos no controle de podridões em maçã 'Fuji' com o uso de fosfito antes do armazenamento (Brackmann et al., 2004).

Em maçãs, os elicitores abióticos: UV-C, ozônio, ASM e fosfito ainda não foram investigados como indutores da síntese da fitoalexina trans-resveratrol.

O objetivo deste trabalho foi avaliar o efeito de elicitores abióticos, na indução da síntese de transresveratrol, e sua possível ação no controle de podridão pós-colheita de maçãs 'Gala' e 'Fuji' armazenadas em atmosfera controlada.

\section{Material e Métodos}

O experimento foi conduzido em 2005, no Núcleo de Pesquisa em Pós-colheita da Universidade Federal de Santa Maria. As maçãs 'Gala' e 'Fuji' foram colhidas em um pomar comercial na região de Vacaria, RS, e selecionadas aquelas sem lesão por dano mecânico ou fitopatológico. A unidade experimental foi constituída por 25 frutos representativos. Para a avaliação dos tratamentos quanto às características físico-químicas dos frutos, foram usadas quatro repetições, em delineamento inteiramente casualizado. Foram usadas outras quatro repetições no mesmo delineamento, para a avaliação de podridão.

Os cinco tratamentos foram: controle exposto à atmosfera controlada (AC), irradiação ultravioleta do tipo C (UV-C), ozônio, fosfito e acibenzolar-S-metil (ASM). A irradiação UV-C foi aplicada em uma câmara de irradiação dotada de quatro fontes, com acionamento independente. Foi aplicada a dose de $2,4 \mathrm{~kJ} \mathrm{~m}^{-2}$, à distância de $25 \mathrm{~cm}$ da fonte até a superfície, com comprimento de onda $254 \mathrm{~nm}$ à temperatura de $30^{\circ} \mathrm{C}$. A irradiância UV-C foi obtida por meio de espectroradiômetro, modelo IL 2000, da marca International Light. As doses 
foram calculadas por meio da integração do tempo de exposição e da irradiância de cada fonte, com uso do programa Oringin versão 5,0.

O ozônio foi aplicado durante o armazenamento, em atmosfera controlada, em minicâmaras de 400 L, equipadas com purificador de ar, modelo OTB-10W.C, que produziu ozônio com a concentração de $0,03 \mu \mathrm{L} \mathrm{L}^{-1}$ no interior dessas minicâmaras. A concentração de ozônio, presente no interior das minicâmaras foi determinada pelo método de oxirredução (Machado et al., 1999). A aplicação de fosfito foi feita por imersão, por 3 min, em uma solução de fosfito (Fitofos), com água destilada e deionizada na concentração de $1,27 \mathrm{~g} \mathrm{~L}^{-1} \mathrm{de}$ $\mathrm{P}_{2} \mathrm{O}_{5}$ e $1,18 \mathrm{~g} \mathrm{~L}^{-1}$ de $\mathrm{K}_{2} \mathrm{O}$, e espalhante adesivo Silwet L77 $(0,05 \% \mathrm{v} / \mathrm{v})$. A aplicação de acibenzolar-S-metil (BION) também foi feita por imersão, por $3 \mathrm{~min}$, em uma solução na concentração de $50 \mathrm{mg} \mathrm{L}^{-1}$ e espalhante adesivo Silwet L77 (0,05\% v/v).

Depois de cada tratamento com oito repetições, quatro foram armazenadas em atmosfera controlada, e quatro foram submetidas à inoculação de Penicillium sp. e, posteriormente, armazenadas sob as mesmas condições, em câmaras assépticas separadas.

O Penicillium sp. - coletado dos tecidos de frutos contaminados - foi identificado por sua estrutura morfológica e isolado pelo método de isolamento monospórico. A estirpe isolada foi cultivada em meio batata-dextrose-ágar (BDA) e Mathur. Posteriormente, foi feita diluição dos esporos para 2,4.105 esporos $\mathrm{mL}^{-1}$ com auxílio da câmara de Neubauer. Cada fruto foi perfurado na região equatorial, em dois pontos opostos, com auxílio de uma ponteira com $3 \mathrm{~mm}$ de diâmetro e $5 \mathrm{~mm}$ de profundidade. Em cada ponto, foi inoculado $30 \mu \mathrm{L}$ da suspensão de esporos. Após a secagem, a $20^{\circ} \mathrm{C}$ da alíquota inoculada, os frutos foram armazenados em câmaras assépticas sob as mesmas condições previamente determinadas para as amostras não inoculadas. Após o armazenamento, os frutos foram expostos a $20^{\circ} \mathrm{C}$ por cinco dias, e as lesões foram medidas com auxílio de paquímetro; os patógenos foram novamente isolados das amostras, o que comprova sua patogenicidade pelo postulado de Koch (Fernandez, 1993).

As maçãs foram armazenadas em atmosfera controlada a $0,5^{\circ} \mathrm{C}$, para 'Gala', e $-0,5^{\circ} \mathrm{C}$ para 'Fuji', em minicâmaras de $232 \mathrm{~L}$. A composição atmosférica para 'Gala' foi de: $1,5 \mathrm{kPa}$ de $\mathrm{O}_{2}$ e $2,5 \mathrm{kPa}$ de $\mathrm{CO}_{2}$ e para 'Fuji', $1 \mathrm{kPa}$ de $\mathrm{O}_{2}$ e $<0,5 \mathrm{kPa}$ de $\mathrm{CO}_{2}$. As maçãs
'Gala' e 'Fuji' foram armazenadas por oito e sete meses, respectivamente. As condições de AC foram estabelecidas mediante a instalação da atmosfera; as pressões parciais de $\mathrm{CO}_{2}$ foram obtidas por meio da injeção desse gás nas minicâmaras. Devido à respiração dos frutos, houve consumo de $\mathrm{O}_{2}$ e aumento de $\mathrm{CO}_{2}$, e, para correção desses gases, foi utilizado um analisador automático de $\mathrm{O}_{2}$ e $\mathrm{CO}_{2}$ da marca Kronenberger Systemtechnik, que analisou diariamente as concentrações de gases das minicâmaras. $\mathrm{O} \mathrm{CO}_{2}$ em excesso, resultante do processo respiratório, foi eliminado com o auxílio de um absorvedor que continha solução de hidróxido de potássio. No armazenamento da maçã 'Fuji', foi utilizado hidróxido de cálcio para reduzir a concentração de $\mathrm{CO}_{2}$. O oxigênio consumido pela respiração foi reposto por meio da injeção de ar atmosférico nas minicâmaras. Depois de finalizados os períodos de armazenamento preestabelecidos para cada cultivar, os frutos foram transferidos para câmara onde permaneceram durante cinco dias à temperatura de $20^{\circ} \mathrm{C}$, em ar atmosférico, condição essa ideal para biossíntese da fitoalexina trans-resveratrol, para o desenvolvimento da resposta fisiológica esperada (Cantos et al., 2000).

Após sete e oito meses de armazenamento em atmosfera controlada e após cinco dias de exposição a $20^{\circ} \mathrm{C}$, os frutos foram analisados quanto ao diâmetro de lesões, firmeza de polpa, acidez titulável, sólidos solúveis totais, açúcares redutores e não-redutores.

O diâmetro das lesões foi medido com auxílio de paquímetro, pela medida do diâmetro das lesões desenvolvidas a partir da inoculação do Penicillium sp. A firmeza de polpa foi determinada na região equatorial dos frutos, em dois lados opostos, por meio da remoção de $2 \mathrm{~mm}$ da epiderme, com auxílio de um penetrômetro equipado com ponteira de $11 \mathrm{~mm}$ de diâmetro. A epiderme coletada foi reservada para extração dos compostos fenólicos. A acidez titulável foi obtida por titulometria do suco, previamente extraído de fatias transversais, retiradas da região equatorial das maçãs, com solução de hidróxido de sódio $0,1 \mathrm{~N}$ até $\mathrm{pH} 8,2$, e os resultados foram expressados em meq $100 \mathrm{~mL}^{-1}$. Os sólidos solúveis totais foram mensurados por refratometria, e os valores expressados em ${ }^{\circ}$ Brix com correção da temperatura ambiente. Os açúcares redutores e não-redutores foram determinados segundo o método de Somogyi \& Nelson (Nelson, 1944).

Pesq. agropec. bras., Brasília, v.43, n.9, p.1097-1103, set. 2008 
As amostras para a determinação de trans-resveratrol, polifenóis totais e antocianinas totais foram preparadas realizado a pesagem do fruto - retirada de $2 \mathrm{~mm}$ da casca na região equatorial; pesagem de $30 \mathrm{~g}$ de cascas - adição de $90 \mathrm{~mL}$ da dissolução de etanol/ ácido clorídrico/água, na proporção de 70/1/30 (V/V/V) e homogeneização em liqüidificador a $87.000 \mathrm{rpm}$ por $1 \mathrm{~min}$, e centrifugação a $10.000 \mathrm{~g}$ por $15 \mathrm{~min}$. Somente as amostras destinadas para análise de cromatografia líquida de alta eficiência (CLAE) foram filtradas em membrana com poro de $0,22 \mu \mathrm{m}$ e congeladas a $-20^{\circ} \mathrm{C}$, até o momento de análise. $\mathrm{O}$ padrão empregado foi trans-resveratrol (trans-3,5,4'-trihidroxiestilbeno) da Sigma Chemical Co.

As análises foram feitas em um sistema híbrido de CLAE, com uso de bomba INTRALAB (Modelo 5050), com detector de diodos DAD HP Series 1100, automatizado por Agilent, controlado com o programa CHEMSTATION Data System software. A coluna de fase reversa foi Merck Nucleosil, C18 (250x4 mm), tamanho de partícula de $5 \mu \mathrm{m}$, com pré-coluna $(10 \times 5 \mathrm{~mm})$ de mesma composição. A injeção de $10 \mu \mathrm{L}$, foi feita com uso do injetor automatizado Agilent (Modelo Series 1100) e a coluna permaneceu aquecida a $30^{\circ} \mathrm{C}$. O método para trans-resveratrol foi com eluição, em condições isocráticas, com fase móvel água/acetonitrila (35:65), pH 2,5, ajustado com ácido ortofosfórico; o fluxo foi de $1 \mathrm{~mL} \mathrm{~min}^{-1} \mathrm{com}$ a eluição monitorada a $306 \mathrm{~nm}$.

A identificação do trans-resveratrol foi baseada no tempo de retenção, e a pureza do pico foi confirmada pelo detector com arranjo de diodos (DAD). A quantificação do trans-resveratrol foi feita por padronização externa e a concentração foi expressada em $\mu \mathrm{g} 100 \mathrm{~g}^{-1}$.

Todas as análises cromatográficas, inclusive a validação do método, foram feitas ao abrigo da luz, a fim de evitar que o isômero trans-resveratrol fosse convertido em cis-resveratrol. Portanto, o estudo da estabilidade foi restringido à temperatura de bancada $\left(25^{\circ} \mathrm{C}\right)$, e armazenamento a $-20^{\circ} \mathrm{C}$, nos diversos tempos.

A validação do método em cromatografia líquida de alta eficiência do analito trans-resveratrol apresentou linearidade $\mathrm{y}=0,0296 \mathrm{x}+0,405$, e coeficiente de correlação de 0,9971 . Os limites de detecção e de quantificação do trans-resveratrol foram obtidos realizando-se diluições gradativas do padrão. O limite de detecção foi de $0,07 \mu \mathrm{g} \mathrm{L}^{-1}$ e o de quantificação de $1,58 \mu \mathrm{g} \mathrm{L} \mathrm{L}^{-1}$. Os testes de recuperação, limite de quantificação e exatidão foram realizados com adição do padrão sobre a matriz. A recuperação média para 'Gala' foi de 98,8\% (CV 5,6\%) e para 'Fuji' foi de 94,1\% (CV 1,7\%). A repetibilidade foi realizada em triplicata. A reprodutibilidade foi feita por meio da análise das variações diárias e em dias diferentes das áreas dos picos dos padrões.

A concentração de polifenóis totais foi determinada pelo método colorimétrico (Singleton \& Rossi Junior, 1965). Em tubo de ensaio, adicionou-se $200 \mu \mathrm{L}$ de amostra diluída (1:10), em solução etanol/ácido clorídrico/água, na proporção de 70/1/30 (V/V/V), $1.000 \mu \mathrm{L}$ de reagente de Folin-Ciocalteu, diluído (1:10) em água destilada e deionizada. Entre $3 \mathrm{~s}$ e $8 \mathrm{~min}$, adicionou-se $800 \mu \mathrm{L}$ de $\mathrm{Na}_{2} \mathrm{CO}_{3} 7,5 \%$. Após duas horas ao abrigo da luz, foi lida a absorbância a $765 \mathrm{~nm}$ em espectrofotômetro da marca FEMTO, modelo 600S (mono feixe). Para a curva de calibração foi utilizada como padrão uma solução de ácido gálico nas concentrações: 50, 100, 150, 250 e $500 \mathrm{mg} \mathrm{L}^{-1}$. A concentração de polifenóis totais foi expressada em mg $100 \mathrm{~g}^{-1}$.

A medida experimental de antocianinas totais foi realizada pela leitura na maior absorbância, e o comprimento de onda selecionado é resultante de varredura entre os comprimentos de 400 e $600 \mathrm{~nm}$, o que determina a antocianina predominante. As amostras foram diluídas com uma dissolução de etanol/ácido clorídrico/água, na proporção de 70/1/30 $(\mathrm{V} / \mathrm{V} / \mathrm{V})$. A leitura foi feita em Espectrofotômetro 600 da marca FEMTO, UV visível. Os resultados foram obtidos $\left(\lambda_{\text {máx }}=525 \mathrm{~nm}\right)$ pela utilização do coeficiente de extinção molar $29,5 \mathrm{~L} \mathrm{~cm}^{-1} \mathrm{~mol}^{-1}$, expressados em miligramas de cianidina por litro e convertidas para mg $100 \mathrm{~g}^{-1}$ (Di Stefano et al., 1989).

Verificou-se as diferenças nas concentrações de polifenóis totais, antocianinas totais, trans-resveratrol, diâmetro de lesão, firmeza de polpa, sólidos solúveis totais, acidez titulável, açúcares redutores e não-redutores entre os diferentes tratamentos.

Foi efetuada uma análise da variância e as médias foram comparadas pelo teste de Tukey, a 5\% de probabilidade. Foi analisada a correlação de Pearson entre a síntese de trans-resveratrol e o controle da podridão. 


\section{Resultados e Discussão}

Após o período de armazenamento, os tratamentos não afetaram os polifenóis totais na casca do fruto (Tabela 1) nem sólidos solúveis totais (Tabela 2), tanto na maçã 'Gala' quanto na 'Fuji'. Com o aumento da temperatura para $20^{\circ} \mathrm{C}$, após o armazenamento, as duas cultivares comportaram-se de modo distinto, fisiologicamente, entre si. A 'Gala' sintetizou mais antocianinas durante o armazenamento com UV-C, mas quinto dia, a $20^{\circ} \mathrm{C}$, não diferiu dos tratamentos-controle, fosfito e ozônio. No entanto, na 'Fuji', as antocianinas não foram influenciadas pelos tratamentos avaliados. O tratamento com acibenzolar-S-metil (ASM) pode ter inibido a síntese ou induzido a degradação dessas antocianinas no quinto dia, a $20^{\circ} \mathrm{C}$, em maçã 'Gala' (Tabela 1), além de ter acelerado a perda de firmeza de polpa (Tabela 2).

Tabela 1. Concentrações médias de compostos fenólicos e controle de podridão (Penicillium sp.) avaliados na saída da câmara e mais cinco dias a $20^{\circ} \mathrm{C}$ em razão dos tratamentos em maçã 'Gala', armazenada em atmosfera controlada (AC) por oito meses a $0,5^{\circ} \mathrm{C}$ e maçã 'Fuji', armazenada em $\mathrm{AC}$ por sete meses a $-0,5^{\circ} \mathrm{C}^{(1)}$.

\begin{tabular}{|c|c|c|c|c|c|c|c|}
\hline \multirow[t]{2}{*}{ Tratamento } & \multicolumn{2}{|c|}{ 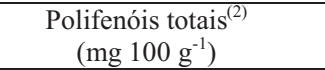 } & \multicolumn{2}{|c|}{$\begin{array}{l}\text { Antocianinas totais } \\
\left(\mathrm{mg} 100 \mathrm{~g}^{-1}\right)\end{array}$} & \multicolumn{2}{|c|}{$\begin{array}{c}\text { Resveratrol }{ }^{(4)} \\
\left(\mu \mathrm{g} 100 \mathrm{~g}^{-1}\right) \\
\end{array}$} & \multirow{2}{*}{$\begin{array}{c}\text { Podridão } \\
\text { Lesão }(\mathrm{cm}) \\
5 \text { dias a } 20^{\circ} \mathrm{C} \\
\end{array}$} \\
\hline & Saída & 5 dias a $20^{\circ} \mathrm{C}$ & Saída & 5 dias a $20^{\circ} \mathrm{C}$ & Saída & 5 dias a $20^{\circ} \mathrm{C}$ & \\
\hline & \multicolumn{7}{|c|}{ Gala } \\
\hline Análise inicial & 249,9 & & 83,0 & & 133,0 & & \\
\hline Testemunha & $371,6 \mathrm{a}$ & $309,1 \mathrm{a}$ & $45,1 \mathrm{~b}$ & $63,6 a$ & $127,7 \mathrm{a}$ & $127,9 a$ & $9,1 \mathrm{a}$ \\
\hline Irradiação (UV-C) & $317,0 \mathrm{a}$ & $355,5 \mathrm{a}$ & $57,8 \mathrm{a}$ & $60,2 \mathrm{a}$ & $126,9 \mathrm{a}$ & $127,2 \mathrm{a}$ & $8,0 \mathrm{a}$ \\
\hline Ozônio & $307,3 \mathrm{a}$ & $326,3 a$ & $47,6 b$ & $64,0 \mathrm{a}$ & $127,9 \mathrm{a}$ & $128,9 \mathrm{a}$ & $8,4 a$ \\
\hline Fosfito & $366,4 a$ & $280,9 a$ & $51,5 b$ & $52,6 \mathrm{a}$ & $128,5 \mathrm{a}$ & $127,7 \mathrm{a}$ & $5,3 \mathrm{~b}$ \\
\hline Acibenzolar-S-metil & $296,6 a$ & $270,8 \mathrm{a}$ & $35,4 b$ & $37,8 \mathrm{~b}$ & $128,9 \mathrm{a}$ & $128,5 \mathrm{a}$ & $7,7 \mathrm{a}$ \\
\hline \multirow[t]{2}{*}{$\mathrm{CV}(\%)$} & 12,8 & 10,0 & 28,5 & 17,7 & 1,5 & 0,5 & 16,6 \\
\hline & \multicolumn{7}{|c|}{ Fuji } \\
\hline Análise inicial & 264,3 & & 7,4 & & 114,4 & & \\
\hline Testemunha & $225,5 a$ & $224,0 \mathrm{a}$ & $13,8 \mathrm{a}$ & $13,2 \mathrm{a}$ & $112,5 b c$ & $121,5 \mathrm{~d}$ & $7,5 \mathrm{ab}$ \\
\hline Irradiação (UV-C) & $246,5 a$ & $188,9 a$ & $15,7 \mathrm{a}$ & $13,7 \mathrm{a}$ & $116,6 b$ & $137,6 \mathrm{bc}$ & $7,6 \mathrm{ab}$ \\
\hline Ozônio & $265,0 \mathrm{a}$ & $253,5 \mathrm{a}$ & $17,6 \mathrm{a}$ & $16,0 \mathrm{a}$ & $106,9 \mathrm{c}$ & $124,6 \mathrm{c}$ & $7,9 \mathrm{a}$ \\
\hline Fosfito & $296,8 \mathrm{a}$ & $227,7 \mathrm{a}$ & $18,4 \mathrm{a}$ & $11,0 \mathrm{a}$ & $106,6 \mathrm{c}$ & $150,2 b$ & $7,0 \mathrm{~b}$ \\
\hline Acibenzolar-S-metil & $254,3 \mathrm{a}$ & $241,1 \mathrm{a}$ & $16,5 \mathrm{a}$ & $10,9 \mathrm{a}$ & $146,3 \mathrm{a}$ & $165,9 \mathrm{a}$ & $7,6 \mathrm{ab}$ \\
\hline $\mathrm{CV}(\%)$ & 8,3 & 6,9 & 24,3 & 14,5 & 11,5 & 11,8 & 4,0 \\
\hline
\end{tabular}

${ }^{(1)}$ Médias seguidas pela mesma letra na coluna, na mesma cultivar, não diferem entre si pelo teste de Tukey, a 5\% de probabilidade. ${ }^{(2)}$ Polifenóis totais em mg de ácido gálico $100 \mathrm{~g}^{-1}$ de massa fresca de casca. ${ }^{(3)}$ Antocianinas totais em mg de cianidina $100 \mathrm{~g}^{-1}$ de massa fresca de casca. ${ }^{(4)}$ Trans-resveratrol em $\mu \mathrm{g} 100 \mathrm{~g}^{-1}$ de massa fresca de casca.

Tabela 2. Médias dos parâmetros físico-químicos avaliados na saída da câmara e mais cinco dias, a $20^{\circ} \mathrm{C}$, em razão dos tratamentos em maçã 'Gala', armazenada em atmosfera controlada (AC) por oito meses, a $0,5^{\circ} \mathrm{C}$, e maçã 'Fuji', armazenada em $\mathrm{AC}$ por sete meses, a $-0,5^{\circ} \mathrm{C}^{(1)}$.

\begin{tabular}{|c|c|c|c|c|c|c|c|c|c|c|}
\hline \multirow[t]{2}{*}{ Tratamento } & \multicolumn{2}{|c|}{$\begin{array}{l}\text { Firmeza } \\
(\mathrm{N})\end{array}$} & \multicolumn{2}{|c|}{$\begin{array}{c}\text { Sólidos solúveis totais } \\
\left({ }^{\circ} \text { Brix }\right)\end{array}$} & \multicolumn{2}{|c|}{$\begin{array}{c}\text { Acidez } \\
\left(\text { meq } 100 \mathrm{~mL}^{-1}\right)\end{array}$} & \multicolumn{2}{|c|}{$\begin{array}{l}\text { Açúcares redutores } \\
\left(\mathrm{g} 100 \mathrm{~mL}^{-1}\right)\end{array}$} & \multicolumn{2}{|c|}{$\begin{array}{l}\text { Açúcares não-redutores } \\
\left(\mathrm{g} 100 \mathrm{~mL}^{-1}\right)\end{array}$} \\
\hline & Saída & 5 dias, a $20^{\circ} \mathrm{C}$ & Saída & 5 dias, a $20^{\circ} \mathrm{C}$ & Saída & 5 dias, a $20^{\circ} \mathrm{C}$ & Saída & 5 dias, a $20^{\circ} \mathrm{C}$ & Saída & 5 dias, a $20^{\circ} \mathrm{C}$ \\
\hline & \multicolumn{10}{|c|}{ Gala } \\
\hline Análise inicial & 79,3 & & 14,3 & & 3,5 & & 8,3 & & 4,7 & \\
\hline Testemunha & $51,0 \mathrm{~b}$ & $60,1 \mathrm{a}$ & $14,3 \mathrm{a}$ & $14,5 \mathrm{a}$ & $4,1 \mathrm{a}$ & $4,0 \mathrm{a}$ & $11,5 \mathrm{a}$ & $11,5 \mathrm{a}$ & $4,7 \mathrm{a}$ & $1,3 \mathrm{a}$ \\
\hline Irradiação (UV-C) & $58,3 \mathrm{a}$ & $58,6 \mathrm{ab}$ & $14,3 \mathrm{a}$ & $14,3 \mathrm{a}$ & $4,0 \mathrm{a}$ & $4,0 \mathrm{a}$ & $12,0 \mathrm{a}$ & $11,9 \mathrm{a}$ & $3,6 \mathrm{a}$ & $1,5 \mathrm{a}$ \\
\hline Ozônio & $49,4 b$ & $53,0 \mathrm{bc}$ & $13,9 \mathrm{a}$ & $14,2 \mathrm{a}$ & $3,6 a$ & $3,9 a$ & $10,8 \mathrm{a}$ & $11,6 \mathrm{a}$ & $3,4 \mathrm{a}$ & $1,7 \mathrm{a}$ \\
\hline Fosfito & $61,0 \mathrm{a}$ & $54,7 \mathrm{abc}$ & $13,8 \mathrm{a}$ & $14,0 \mathrm{a}$ & $3,8 \mathrm{a}$ & $3,7 \mathrm{a}$ & $11,3 \mathrm{a}$ & $11,5 \mathrm{a}$ & $4,8 \mathrm{a}$ & $0,4 \mathrm{a}$ \\
\hline Acibenzolar-S-metil & $58,3 \mathrm{a}$ & $50,7 \mathrm{c}$ & $14,1 \mathrm{a}$ & $14,0 \mathrm{a}$ & $3,9 \mathrm{a}$ & $3,7 \mathrm{a}$ & $11,5 \mathrm{a}$ & $11,5 \mathrm{a}$ & $3,8 \mathrm{a}$ & $0,4 \mathrm{a}$ \\
\hline \multirow[t]{2}{*}{ CV (\%) } & 16,1 & 6,2 & 1,5 & 1,2 & 5,6 & 3,5 & 11,0 & 1,2 & 13,6 & 0,0 \\
\hline & \multicolumn{10}{|c|}{ Fuji } \\
\hline Análise inicial & 76,9 & & 16,6 & & 5,5 & & 9,9 & & 2,5 & \\
\hline Testemunha & $74,7 \mathrm{ab}$ & $71,5 \mathrm{a}$ & $16,6 \mathrm{a}$ & $17,0 \mathrm{a}$ & $3,6 \mathrm{a}$ & $3,7 \mathrm{ab}$ & $12,6 \mathrm{ab}$ & $12,0 \mathrm{ab}$ & $0,0 \mathrm{~b}$ & $4,3 \mathrm{a}$ \\
\hline Irradiação (UV-C) & $78,7 \mathrm{a}$ & $68,4 a$ & $16,8 \mathrm{a}$ & $17,0 \mathrm{a}$ & $3,9 \mathrm{a}$ & $3,7 \mathrm{a}$ & $12,9 \mathrm{ab}$ & $9,5 b$ & $2,0 \mathrm{ab}$ & $4,6 \mathrm{a}$ \\
\hline Ozônio & $71,7 \mathrm{~b}$ & $70,0 \mathrm{a}$ & $16,8 \mathrm{a}$ & $17,1 \mathrm{a}$ & $3,9 a$ & $3,6 a b$ & $14,5 \mathrm{a}$ & $10,1 b$ & $0,0 \mathrm{~b}$ & $3,8 \mathrm{a}$ \\
\hline Fosfito & $75,4 \mathrm{ab}$ & $69,7 a$ & $16,6 a$ & $16,8 \mathrm{a}$ & $3,7 \mathrm{a}$ & $3,3 \mathrm{c}$ & $12,4 \mathrm{ab}$ & $8,7 \mathrm{~b}$ & $0,6 \mathrm{~b}$ & $4,4 \mathrm{a}$ \\
\hline Acibenzolar-S-metil & $74,1 \mathrm{ab}$ & $70,7 \mathrm{a}$ & $16,7 \mathrm{a}$ & $17,3 \mathrm{a}$ & $3,7 \mathrm{a}$ & $3,5 \mathrm{bc}$ & $9,8 \mathrm{~b}$ & $14,9 \mathrm{a}$ & $4,6 \mathrm{a}$ & $0,1 \mathrm{~b}$ \\
\hline $\mathrm{CV}(\%)$ & 28,8 & 14,2 & 0,9 & 1,0 & 16,2 & 3,9 & 13,9 & 20,3 & 100,3 & 0,0 \\
\hline
\end{tabular}

${ }^{(1)}$ Médias seguidas pela mesma letra na coluna, na mesma cultivar, não diferem entre si pelo teste de Tukey, a $5 \%$ de probabilidade. 
Os níveis de polifenóis totais, trans-resveratrol, sólidos solúveis totais, acidez titulável e açúcares redutores e não redutores da maçã 'Gala' não foram alterados com o uso de elicitores (Tabela 2), porém o controle da podridão foi obtido com a aplicação de fosfito (Tabela 1). Nesse caso, não há correlação entre o controle da podridão com a concentração da fitoalexina trans-resveratrol (correlação de Pearson: $-0,01 \mathrm{p} \alpha$ 0,966). O mecanismo de defesa do hospedeiro (planta) ainda não é completamente conhecido, mas o ânion fosfito tem sido relacionado ao aumento da zona bloqueadora da necrose, rápida mudança citológica pela migração nuclear, deposição de papila e aumento da resposta de hipersensibilidade (morte celular) (Guest \& Grant, 1991). No hospedeiro, também ocorre a biossíntese de etileno, aumento da respiração, ativação da fenilalanina amonialiase (FAL), lignificação, ativação do metabolismo das pentoses-fosfato e, entre as fitoalexinas, encontramse sesquiterpenóides, em tabaco e polifenóis (Guest \& Grant, 1991). Em feijão-fradinho (Vigna unguiculata), experimentos com fosfanato demonstram o acúmulo de fitoalexinas como kievitone e faseolidina, em plantas infectadas (Saindrenan et al., 1990). Jackson et al. (2000), ao estudar eucalipto, não observaram mudanças significativas em duas enzimas-chave da síntese de diversos fenóis simples (4-coumarato CoA ligase [4-CL], cinamil álcool desidrogenase [CAD]), mas verificaram que, quando a concentração de fosfito é alta, a ação é direta sobre o fungo, e, quando a concentração é baixa, a planta tem um aumento em sua resistência natural. Os resultados obtidos neste trabalho foram semelhantes aos obtidos por Brackmann et al. (2004). Esses autores verificaram que a aplicação em pós-colheita, em maçãs 'Fuji', tratadas com fosfito de potássio $\left(250 \mathrm{~mL} 100 \mathrm{~L}^{-1}\right)+\mathrm{CaCl}_{2}(2 \%)$, proporcionou menor incidência de podridões e menor diâmetro de lesão.

A cultivar Fuji respondeu a todos os tratamentos com elicitores, tendo sintetizado trans-resveratrol, mas sem alterações na concentração de polifenóis totais ou antocianinas totais (Tabela 1). O primeiro composto formado na família dos estilbenos é o resveratrol, seguido de $\varepsilon$-viniferin, $\alpha$-viniferin, glucosídeo e demais polímeros do resveratrol (Culver, 1995; Soleas, 1997; Goodwin, 1988). Portanto, a concentração de resveratrol, em relação aos polifenóis totais e às antocianinas totais, é reduzida, o que pode explicar os resultados da Tabela 1. Logo após o armazenamento, o acibenzolar-S-metil induziu a síntese de resveratrol seguido dos demais tratamentos. Porém, após os cinco dias, a $20^{\circ} \mathrm{C}$, o aumento na concentração de trans-resveratrol foi maior para acibenzolar-S-metil, seguido do fosfito, irradiação UV-C e ozônio. Também em 'Fuji', não há correlação (correlação de Pearson: $0,05 \mathrm{p} \alpha$ 0,836) entre a produção de trans-resveratrol e o controle do Penicillium sp. Após o período de armazenamento de sete meses em AC; nenhum elicitor apresentou efeito significativo no controle de podridão. Esses resultados são divergentes aos obtidos por Brackmann et al. (2004), o que se deve, provavelmente, ao fato de que o período de armazenamento foi de 14 dias, a $0^{\circ} \mathrm{C}$, em contraste com o presente trabalho, que permaneceu sete meses na câmara a $-0,5^{\circ} \mathrm{C}$. Da mesma forma, Spadaro et al. (2004), com uso de ASM em 'Golden Delicious', obtiveram controle de $B$. cinerea e $P$. expansum com 20 dias de armazenamento, a $4^{\circ} \mathrm{C}$. No presente trabalho, o ASM não controlou Penicillium sp., em sete meses de armazenamento a $-0,5^{\circ} \mathrm{C}$, porém foi o melhor tratamento para indução de trans-resveratrol, em 'Fuji', e mobilizou, de forma significativa, os açúcares não-redutores a redutores, o que sinaliza aumento do metabolismo (Tabela 2).

\section{Conclusões}

1. Os elicitores abióticos induzem a síntese da fitoalexina trans-resveratrol em maçã 'Fuji' na seqüência: acibenzolar-S-metil $>$ fosfito $\geq$ irradiação UV-C $\geq$ ozônio, mas não apresentam efeito em maçãs 'Gala', durante o armazenamento em atmosfera controlada.

2. Não há aumento na concentração dos polifenóis totais e das antocianinas totais com o uso de elicitores abióticos.

3. Os elicitores abióticos não apresentam efeito no controle de podridão, com exceção do fosfito, que controla a podridão em maçã 'Gala'.

4. Não há correlação entre a síntese de trans-resveratrol e o controle de podridão.

\section{Agradecimentos}

À Coordenação de Aperfeiçoamento de Pessoal de Nível Superior, pelo apoio financeiro; à Interozone do Brasil, pelo apoio técnico. 


\section{Referências}

ADRIAN, M.; JEANDET, P.; DOUILLET-BREUIL， A.C.; TESSON, L.; BESSIS, R. Stilbene content of mature Vitis vinifera berries in response to UV-C elicitation. Journal of Agricultural and Food Chemistry, v.48, p.6103-6105, 2000.

ARTÉS-HERNÁNDEZ, F.; ARTÉS, F.; TOMÁS-BARBERÁN, F.A. Quality and enhancement of bioactive phenolics in cv. Napoleon table grapes exposed to different postharvest gaseous treatments. Journal of Agricultural and Food Chemistry, v.51, p.5290-5295, 2003.

BRACKMANN, A.; GIEHL, R.F.H.; IVAN SESTARI, I.; STEFFENS, C.A. Fosfitos para o controle de podridões pós-colheita em maçãs 'Fuji' durante o armazenamento refrigerado. Ciência Rural, v.34, p.1039-1042, 2004.

BRASIL. Ministério da Agricultura, Pecuária e Abastecimento. Instrução Normativa № 20, de 27 de setembro de 2001. Aprova as diretrizes gerais para a produção integrada de frutas - DGPIF e as normas técnicas gerais para a produção integrada de frutas - NTGPIF. Diário Oficial [da] República Federativa do Brasil, Brasília, DF, 15 out. 2001. Seção 1, p.40-44.

CANTOS, E.; GARCÍA-VIGUERA, C.; PASCUAL-TERESA, S.; TOMÁS-BARBERÁN, F.A. Effect of postharvest ultraviolet irradiation on resveratrol and other phenolics of cv. Napoleon table grapes. Journal of Agricultural and Food Chemistry, v.48, p.4606-4612, 2000.

CONRATH, U.; THULKE, O.; KATZ, V.; SCHWINDLING, S.; KOHLER, A. Priming as a mechanism in induced systemic resistance of plants. European Journal of Plant Pathology, v.107, p.113-119, 2001.

CULVER, J.N. Molecular strategies to develop virus resistant plants. In: SINGH, R.P.; SINGH, U.S. Molecular methods in plant pathology. New York: CRC Press, 1995. p.235-249.

DI STEFANO, R.; CRAVERO, M.C.; GENTILINI, N. Metodi per lo studio dei polifenoli dei vini. L'Enotecnico, v.25, p.83-89, 1989 .

DURRANT, W.E.; DONG, X. Systemic acquired resistance. Annual Review of Phytopathology, v.42, p.185-209, 2004.

FERNANDEZ, M.R. Manual para laboratório de fitopatologia. Passo Fundo: Embrapa-CNPT, 1993 128p.

FRÉMONT, L. Minireview: biological effects of resveratrol. Life Sciences, v.66, p.663-673, 2000.

GOODWIN, T.W.; MERCER, E.I. Introduction to plant biochemistry. 2.ed. London: Pergamon Press, 1988. 677p.

GRIMMIG, B.; GONZALEZ-PEREZ, M.N.; LEUBNERMETZGER, G.; VÖGELI-LANGE， R.; FRED MEINS JUNIOR, F.; HAIN, R.; PENUELAS, J.; HEIDENREICH, B.; LANGEBARTELS, C.; ERNST, D.; SANDERMANN JUNIOR, $\mathrm{H}$. Ozone-induced gene expression occurs via ethylene-dependent and -independent signalling. Plant Molecular Biology, v.51, p.599-607, 2003.

GRIMMIG, B.; GONZALEZ-PEREZ, M.N.; WELZL， G.; PENUELAS, J.; SCHUBERT, R.; HAIN, R.; HEIDENREICH, B.; BETZ, C.; LANGEBARTELS, C.; ERNST, D.; SANDERMANN JUNIOR, H. Ethylene- and ozone-induce regulation of a grapevine resveratrol synthase gene: different responsive promoter regions. Plant Physiology and Biochemistry, v.40, p.865-870, 2002.

GUEST, D.; GRANT, B. The complex action of phosphanates as antifungal agents. Biological Reviews, v.66, p.159-187, 1991.

HUANG, Y.; DEVERALL, B.J.; TANG, W.H.; WANG, W.; WU, F.W. Foliar application of acibenzolar-S-methyl and protection of postharvest rock melons and Hami melons from disease. European Journal of Plant Pathology, v.106, p.651-656, 2000.

JACKSON, T.J.; BURGESS, T.; COLQUHOUN, I.; HARDY, G.E.S. Action of the fungicide phosphite on Eucalyptus marginata inoculated with Phytophthora cinnamomi. Plant Pathology, v.49, p.147-154, 2000.

MACHADO, E.L.; ROSA, M.B. da; FLORES, E.M.M.; PAINZ, J.N.G.; MARTINS, A.F. Spectrophotometric determination of ozone in ozonized air currents with chemical gas-liquid transfer using a microreactor. Analytica Chimica Acta, v.380, p.93-100, 1999.

NELSON, N. A photometric adaptation of the Somogyi method for the determination of glucose. Journal of Biological Chemistry, v.153, p.375-380, 1944.

PINTO, M.C.; GARCÍA-BARRADO, J.A.; MACÍAS, P. Resveratrol is a potent inhibitor of the dioxygenase activity of lipoxygenase. Journal Agricultural Food Chemistry, v.47, p.4842-4846, 1999.

SAINDRENAN, P.; BARCHIETTO, T.; BOMPEIX, G. Effects of phosphonate on the elicitor activity of culture filtrates of Phytophthora cryptogea in Vigna unguiculata. Plant Science, v.67, p.245-251, 1990.

SCHWAN-ESTRADA, K.R.F.; STANGARLIN, J.R.; CRUZ, M.E. da $\mathrm{S}$. Uso de extratos vegetais no controle de fungos fitopatogênicos. Floresta, v.30, p.129-137, 2000.

SINGLETON, V.L.; ROSSI JUNIOR, J.A. Colorimetry of total phenolics with phosphomolybdic-phosphotungstic acid reagents. American Journal of Enology and Viticulture, v.16, p.144-158, 1965.

SOLEAS, G.J.; DIAMANDIS, E.P.; GOLDBERG, D.M. Resveratrol: A molecule whose time has come? And gone? Clinical Biochemistry, v.30, p.91-113, 1997.

SPADARO, D.; GARIBALDI, A.; GULLINO, M.L. Control of Penicillium expansum and Botrytis cinerea on apple combining a biocontrol agent with hot water dipping and acibenzolar-S-methyl, baking soda, or ethanol application. Postharvest Biology and Technology, v.33, p.141-151, 2004.

Recebido em 24 de março de 2008 e aprovado em 21 de agosto de 2008 
